\title{
Paper on: Human Rights Entitle to Preserve Separate Identity under the FDRE Constitution: Problems, Challenges and Future Trends
}

\section{Belete Mehari*}

Department of Civics and Ethical Study, University of Gondar, Ethiopia

\begin{abstract}
The 1995 FDRE Constitution establishes an ethnic based federal state structure. The new political system recognizes the fundamental rights and freedoms of the Ethiopian Nations, Nationalities and Peoples to exercise the right to self-determination up to and including secession and other identity related rights as solutions to the earlier unequal relationships among ethno-national groups in the country. With that in mind, this paper has four main parts. First, it states the constitutional recognition of ethnic groups under the constitution. In the second part, an attempt will be made to examine the rights that help to preserve separate identity and related right in the FDRE constitution. Third, it analyzes the challenges and problems to exercise the rights entitle to separate identity in the perspective of ethnic federalism in Ethiopia. Fourth, it attempts to speculate on its future prospects. And finally, it concludes by summarizing the main points of all sections.
\end{abstract}

\section{Keywords: Arts; Social; Science}

Abbreviations: FDRE: Federal Democratic Republic of Ethiopia; HoF: House of Federation; HPR: House of Peoples Representatives; ICCPR: International Covenant on Civil and Political Rights; ICESCR: International Covenant on Economic, Social and Cultural Rights; MDG: Millennium Development Goal; NNP: Nations, Nationalities and Peoples; SNNP: Southern Nations, Nationalities and Peoples; SNNPRS: Southern, Nations, Nationalities and Peoples Regional State; TGE: Transitional Government of Ethiopia; UDHR: Universal Declaration of Human Rights

\section{Introduction}

In 1991 Ethiopia established an ethnic federal system that gave full recognition to ethnic groups to preserve their separate identity, in order to maintaining the unity of the state. Then, in 1995 the FDRE Constitution established an ethnic based federal state consisting of regional states delineated on the basis of settlement patterns, language, identity, and consent of the people concerned. The rationale for this type of "ethnic federalism" was to offer an opportunity to promote the rights and benefits of ethnic groups in Ethiopia. For this reason, the constitution devotes more than one third of its content to provisions on fundamental human and people's rights. ${ }^{1}$ From those provisions, our concern here is on rights that help to preserve separate identity and related rights which are given to all NNP in Ethiopia.

However, Practically the Ethiopian federal arrangement is problematic and challenging for the realization of the right to selfdetermination and some other identity related rights. The ethnic makeup and structure in Ethiopia reveal the difficulties associated with the discourse of self-determination to every NNP in Ethiopia. Specifically, it is difficult to established self-rule and exercise linguistic rights in the complex variety of nations, nationalities and peoples, and linguistic groups in a certain regional states. ${ }^{2}$ This creates further problems to exercise other identity related rights.

Consequently, Constructing and initiating ethnic pillars are very destructive in the long run due to the narrow and egocentric nature of

${ }^{1}$ Abebe AK (2011). Human Rights under the Ethiopian Constitution: A Descriptive Overview, Mizan Law Review, 5(1): 44-47.

${ }^{2}$ Brhanu Gutema, (2007). Restructuring State and Society: Ethnic Federalism in Ethiopia. ethnic demands. In addition, it is very difficult to satisfy identity related rights in poor country like Ethiopia which ethnic demand needs ample economic recourses. ${ }^{3}$ For this reason, it will be advisable to emphasize incentives for socio-economic and political integration rather than focusing on distinctiveness and differences.

\section{Recognition of Identity under the FDRE Constitution}

Ethiopia is country of more than $80 \mathrm{NNP}$. Much of these NNP have their own distinct culture, history, language and way of life, they have also a history which they share in common. The first thing that comes into the picture of discussion of ethnic groups and their rights is official recognition. It is the recognition of ethnic groups that gives rise to other rights. Each ethnic, linguistic, cultural or religious group has the right to existence that should be recognized by the constitution. Denial of such recognition implies denial of their existence and this is a clear violation of human rights. For this purpose Ethiopian Federalism might be the best political framework in the existence of essentially permanent religious, ethnic, cultural, or social groups in order to accommodate the diverse socio-political interest. ${ }^{4}$ We also believed that territorial divisions of power can be used to protect ethnic group's rights by allowing them to determine their own destiny, to learn in their local language, and to preserve their own culture and history.

Currently the identity of each ethnic group recognized in the constitution that gives the way to exercise the right to separate identity. For this purpose the FDRE constitution Art.39 (5) defines NNP as IIbid p: 268

${ }^{4}$ Shibeshi B (2010) Minority rights protection in the Amhara national regional state: The case of the kemant people in north Gondar, p: 27.

*Corresponding author: Belete Mehari, Department of Civics and Ethical Study, University of Gondar, Ethiopia, Tel: +0910809342; E-mail: betetem48@gmail.com

Received December 06, 2017; Accepted December 29, 2017; Published January 01,2018

Citation: Mehari B (2018) Paper on: Human Rights Entitle to Preserve Separate Identity under the FDRE Constitution: Problems, Challenges and Future Trends. Arts Social Sci J 9: 328. doi: 10.4172/2151-6200.1000328

Copyright: (๑) 2018 Mehari B. This is an open-access article distributed under the terms of the Creative Commons Attribution License, which permits unrestricted use, distribution, and reproduction in any medium, provided the original author and source are credited. 
a group of people who have or share a large measure of a common culture or similar customs, mutual intelligibility of language, belief in a common or related identities, a common psychological make-up, and who inhabit an identifiable, predominantly contiguous territory. For this reason, the Process to attain the status of 'nation, nationality and people' is determined based on these criteria. Based on this the constitution established the country as a federation of multi-ethnic nation, identified nine states based on ethno-linguistic line as the subnational entities that constitute the Ethiopian federation. ${ }^{5}$ This structure gives opportunities to protect the right to preserve separate identity of ethnic groups.

\section{The Rights to Preserve Separate Identity under the FDRE Constitution}

The Ethiopian population is characterized by considerable diversity in religion, language, culture, socio-economic activities and traditional governance structures. ${ }^{6}$ These distinct identities of ethnic groups such as linguistic, religious, cultural and political identities can be a point of concern when the right to physical existence should be respected. This right to physical existence implies not a mere continuance of ethnic groups as a separate entity, but it also extends to include all necessary political, social, economic and moral facilities to retain and promote their distinct identities ${ }^{7}$.

The 1995 Constitution provides broad human rights protections in conformity with international human rights laws and principles. Onethird of the Constitution is devoted to the recognition and protection of human rights. In addition to individual rights, the Constitution espouses commitment to ethnic group rights. The special features of the Constitution include the recognition given to the ethnic diversity and the willingness to accommodate it through the right to selfdetermination. ${ }^{8}$ Thus, the beneficiaries of all aspects of the right to self-determination under the constitution are the NNP of Ethiopia. Interestingly, an identity of ethnic group is identified in relation to their cultural, ethnic, linguistic and religious identities which are aspects and components of self-determination.

\section{The right to self determination}

The principle of self-determination is not a recent phenomenon as some may expect. In various forms, the principle of self-determination has long been a central political and legal claim in world history. For instance, in 1948 the claims for self-government against imperial rulers in Europe resulted in the Westphalia treaties that declared autonomy and independence for nation states. In 1945 the UN charter proclaimed that one of the purposes of the organization is to develop friendly relations among nations based on the respect for the principle of equal rights and self-determination of peoples. In 1960, the UN declaration on the granting of independence to colonial countries and peoples proclaimed that all peoples have the right to self-determination. ${ }^{9}$ Currently, the right to self-determination being a fundamental and inalienable human right which is found in two major human rights instruments such as

${ }^{5}$ FDRE 1995, The Constitution of The Federal Democratic Republic of Ethiopia.

${ }^{6}$ Christophe VB (2007) Ethiopia: Constitutional protection of Ethnic Minorities at Regional level, African Focus, 20: 1.

${ }^{7}$ Daba T (2010) The Legal and Practical Protection of the Rights of Minorities in Self Administering Nations of Ethiopia: The Case of Oromia.

${ }^{8}$ Mgbako C (2008) Silencing the Ethiopian courts: non judicial constitutional review and its impacts on human rights. Fordham International Law Journal 32(1): 259.

${ }^{9}$ Girmachew et al. (2013) Ethiopian human rights handbook: school of law and center for human rights, Addis Ababa University.
ICCPR and ICESCR. For instance, Art.1 of the ICCPR states that, "all peoples have the right to self-determination so that by virtue of that right they can freely determine their political status; freely pursue their economic, social and cultural development. ${ }^{10}$

According to the new conception of ethnic federalism, the construction of an Ethiopian National identity was based on the recognition of the ethnic diversity of the peoples. In other words, unity depended on the recognition of and the respect for diversity. This attention to unity in diversity was legally expressed in the granting of a right to self-determination to all the NNP (the Ethiopian constitutional term for ethnic groups) of Ethiopia. The right to selfdetermination under the Ethiopian constitution has got multiple pillars and interrelated aspects which include language rights, cultural rights, rights to self-government and other related rights. It even includes the right of NNP to secede from the Ethiopian federation. ${ }^{11}$

Linguistic rights: Language is an indispensable attribute of human being not only for a medium of communication but also it is "a source of pride, self-esteem and identity" in the sense that it is a defining characteristic of human society. It plays valuable role for diplomatic co-existence and social life of human beings. Language is an intrinsic element of identity of human person. It serves as store house of ethnic groups' culture, history, tradition and, in effect of their identity. ${ }^{12}$

For this reason, Art. 27 of ICCPR have given recognition to the right of linguistic minorities to use their language. The FDRE Constitution has also given equal state recognition to all Ethiopian language (Art. $5 / 1$ and 9/4) and it also gives the right for members of the federation to determine their respective working language by law (Art. 5/3). Moreover, Art. 39/2 gives to every Nation, Nationality and People in Ethiopia the right to speak, to write and develop its own language. It is thus not surprising that since the promulgation of the Constitution there have taken place a number of practical changes in the use of many languages as working languages at the regional and state level and the use of different languages at least at primary educational level. For instance, the current practice in the use of mother tong in primary Education is a good start in the right direction of promoting ethnic groups' linguistic rights and implementing the universal access of primary education to all in 2015 as a MDG. In view of ethnic groups rights and the pedagogical value of mother tongue education at primary level the current practices in Ethiopia can be viewed as best practice to be exercise linguistic rights. ${ }^{13}$

I also believe that linguistic rights in the constitution give equal opportunity for all ethnic groups to preserve their distinct identity, and equally participate in political, social and economic affairs.

Cultural rights: The right to maintain one's separate identity of ethnic groups can be meaningful only when each group exercises, practices and develops its cultural assets in addition to their own language. Ethnic groups can make its cultural, traditional and customary values everlasting and cross-generational only through practice. As to the contents of 'cultural rights; customs, morals, traditions, rituals, types of housing, wearing, eating habits, the cultivation of music, the establishment of cultural organizations, the publication of literatures in

\section{${ }^{10}$ See the 1996 ICCPR and ICESCR (Art.1)}

${ }^{11}$ Supra note. 6 pp: 106-107.

${ }^{12}$ Supra note. 7 p: 39.

${ }^{13}$ Taye H (2012). Issues of Minority Rights in the Ethiopian Federation: ECMI Working Paper pp: 11-12 
the ethnic group language' may be few. ${ }^{14}$

The 1995 constitution recognized cultural pluralism, all ethnic groups should have the opportunity to practice, develop, promote and educate their generation about their culture, and states should facilitate by extending preferential treatments depending on consciousness of the ethnic group and economic viability of the state in which each group reside. Article 91 of the FDRE constitution provides major obligation of the state for the protection of the right to culture. According to sub article 1of such article the government has the duty to support, on the basis of equality, the growth and enrichment of cultures and traditions as long as these traditions are compatible with the fundamental rights, human dignity and democratic norms and ideals..$^{15}$

The right to preserve one's history: The Ethiopian NNP were the kind of proud people who had all the way managed to successfully defend their sovereignty and their country against any foreign aggressors. They also, have been their own local and ethnic traditional moral codes throughout their history. ${ }^{16}$ Presently, the FDRE constitution, Art.39 provides the right for all NNP of Ethiopia to preserve its own history.

Rights to self-government: The right to self-government relates with a certain degree of political and economic autonomy at every level of the state system vis-à-vis the federal government. For this reason, Art 50 (8) of the constitution determines the extent of self-rule of the NNP by allocating range of powers to the regional states and delimiting the jurisdictions of the federal government. Article 88(1) of the constitution stipulates that the Ethiopian government must support and promote the right to self-rule. ${ }^{17}$ Interestingly, Art.39 (3) of the constitution also provides the right to "a full measure of self-government" to all NNP. This implies first the establishment of institution of government by NNP on its identifiable contiguous territory. Secondly, it implies equitable representation at the federal government and the state. To realize the right to self-determination, the federal constitution guarantees the representation of the ethnic groups in the federal institutions. The federal parliament is composed of two chambers: the HPR and HOF. The HPR is composed of a maximum of 550 members elected for a five-year term based on population size which represent the Ethiopian people as a whole. From these, minority Nationalities and Peoples shall have at least 20 seats to approve equal representation at the center. Art 61 of the constitution states that the HOF is the second chamber in the federal government composed of representatives of, nation's nationalities and peoples. Each NNP shall be represented in the House of the federation by a least one member. Each Nation or Nationality shall be represented by one additional representative for each one million of its population. The HOF is given the most important power of the interpretation of the FDRE constitution and it also empowered to decide up on issues related to the rights of states to self-determination including secession. ${ }^{18}$

The right to session: The right to secession is also part and parcel of the right to self-determination of nations regardless of their numerical, historical and political status. Unlike other federations the right to secession is also included under the notion of the right to selfdeamination in the 1995 constitution. The preconditions for secession are listed under Article 39 (4): a two-thirds majority support of the

${ }^{14}$ Supra note 7 p: 42

${ }^{15}$ Supra note 5

${ }^{16}$ Fasil Nahum, Constitution for a Nation of Nations: The Ethiopian Prospect. Asmara/Trenton, NJ: Red Sea Press, 1997.

${ }^{17}$ Regassa T, State Constitutions in Federal Ethiopia: A preliminary observation, Bellagio Conference, 2004, p: 2.

${ }^{18}$ lbid.
Legislative Council of the nation, nationality and people concerned; a simple majority vote in a referendum to be organized in a maximum of three years from the time the demand has been espoused by the relevant Legislative Council, and when transfer of power and division of assets has been effected. All this process is conducted under the auspices of the House of Federation. ${ }^{19}$

The right to religion: Freedom of religion is one of the fundamental rights of individuals. Everyone has the right to freedom of thought, conscience and religion. This right shall include the freedom to hold or to adopt a religion or belief of his choice, and the freedom, either individually or in communally with others, and in public or private, to manifest his religion or belief in worship, observance, practice and teaching. Thus, ethnic groups who desire to preserve their religious identities with equal footing with other religious groups need to Protection. For this reason, Separation of state and religion are guaranteed under Art.11 of the FDRE Constitution and none of them interfere in the matters of the other. In addition, freedom of religion and belief is guaranteed, and believers have a right to establish institutions of religious education and administration. ${ }^{20}$ In addition to these, there are some identity related rights which are recognized under the FDRE constitution. The right to equality is one from them.

Right to equality: The right to equality is needed in multi-ethnic state so as to distribute ethno-national justice among ethnic groups beside among individuals. The FDRE Constitution assumes an obligation to respect and promote the right of citizens and nations and rule of law. The Constitution states everyone is equal before the law without any discrimination based on race, national, nationality or other social origin, color, sex, language, religion, political or other opinion, property, birth or other status. The right to equality and non-discrimination are relevant and essential elements of individual and ethnic groups. Thus, each ethnic groups have express their characteristics and to develop their culture, language, religion, traditions and customs with equal footing with the other ethnic groups. ${ }^{21}$

\section{Problems and Challenges}

It is very difficult and challenging to sustain the ideology of ethnic entitlement in the context of Ethiopia which has been influenced by centuries of migration and interaction between ethnic groups, who has created a complex pattern of ethnic, linguistic and religious groups. For this reason, the introduction of ethnic entitlement has a source of human right abuse in Ethiopia. ${ }^{22}$

In fact, there is ambiguity in the constitution that declares the rights of self-government for every ethnic group in Ethiopia. It becomes a challenging task to adequately and fairly represent the 80 ethnic groups in nine regional states. Only few ethnic groups like the Tigrean, Afar, Amhara, Oromo, Somali and Harari have got a privileged position and right to satisfy their rights for self-government from the total of about 80 ethnic groups that are promised to have their own self-administration rights. Thus, it may be difficult to satisfy all the demands of ethnic groups to have regional, Zonal or Woreda level autonomy in the existence of heterogeneous ethnic groups in the remaining regional states. ${ }^{23}$

For instance, in the SNNP regional state which is home to about ${ }^{19}$ Supra note 1 p: 56

${ }^{20}$ Supra note 4 p: 48.

${ }^{21}$ Supra note. 7 p: 45.

${ }^{22}$ Supra note .2 p: 218

${ }^{23}$ Ibid p: 124 
60 officially registered ethnic groups, an attempt has been made to create ethnically delimited administrative structures at zonal and wereda levels, despite the rare existence of ethnically homogeneous zonal or wereda territories. In fact, the greater majority, two-third of the ethnic groups share the same zonal or wereda administrations with other ethnic groups without having been accorded their own selfadministration status, which is promised in the federal and regional constitutions. ${ }^{24}$ From this fact, We have stated that the right to selfdetermination is not realizing without the establishment of self-rule for each NNP of Ethiopia. For instance, would you exercise the right to political participation without establishing self-rule? Of course not, in multi-ethnic regions only some ethnic groups have the right to selfrule.

Furthermore, the constitution did not make or present any convincing explanation to form the nine regional states; the criteria are not clear or not consistently applied based on Art 46(2) of the constitution. For instance, No clear explanation was provided for the inclusion of Harari among states without numerical, territorial, economic, and political strength and exclusion of others who are significant population and better economic capacity that can fulfill the working procedure to get a separate regional self-government such as Sidama, Gurage and Wolayita are compacting with numerous ethnic groups in southern Ethiopia in a single regional self-government structure..$^{25}$ Thus, this complex structure of Ethiopian federalism is a challenge for exercising the right to self-rules and other aspects of selfdetermination. For instance, what happen in the case where a state's exercise of the right to secede contradicts the wishes of one or several indigenous or exogenous ethnic communities within its borders opting to remain united with the rest of Ethiopia? It is difficult to apply the states like Benishangul/Gumuz, SNNPRS and Gambella since, each of these states belongs to the multifarious ethnic groups that reside within its geographical boundaries collectively which no particular groups has an exclusive claim to right to secede.

The other problem is relating to the exercise of linguistic rights. It looks that Art. 5(1) and (2) of the FDRE Constitution contradict each other because it is difficult to give equal state recognition to all languages in the existence of one federal working language. For instance, Tigray, Afaan Oromo, Amharic, recently Afar and Somali languages are used for daily National TV programs where as several Ethiopian languages are used for local radio stations in the area where they are spoken and still there are many languages which are not even used for local radio stations. ${ }^{26}$

In addition, even if the government has recognized the rights of ethnic groups to learn in their own language and to develop a cultural sensitive curriculum, it is difficult to exercise such demands for all ethnic groups in the existence of wide range of language spoken in Ethiopia. The financial capacity and trained manpower availability to provide primary education in all Ethiopian language is the challenge that faces the Ethiopian government. Furthermore the quality of education is one of the hotly debated issues currently in the Ethiopian public and scholars of education. ${ }^{27}$ For instance, it is challenging to training personnel in all NNP languages that forced children to learn by other language that affect the quality of education.

${ }^{24}$ Supra note .2 p: 208

${ }^{25}$ Ibid pp: $124-125$

${ }^{26}$ Supra note. 7 p: 68

${ }^{27}$ Supra note. 13 p: 11

\section{Some other practical problems}

The other problematic issue in relation to the right to selfdetermination arose from exogenous groups who live outside of their region. In Ethiopia due to demographic and political factor in the past people of different backgrounds move, migrate and intermix especially when they share common economic and political community. While the 1995 Constitution so generously recognizes the right to selfdetermination of ethno-national groups, it utterly fails to pay any attention to the non-indigenous groups who find themselves outside their regional states. For this reason, majority of the Amhara who inhabit the Oromia State or the Beneshangul-Gumuz State are not treated as a group of people with the right to exercise some political and lingustic rights. They cannot establish their political organization to participate in the conduct of regional or local governments. ${ }^{28}$ These hinder exogenous groups to exercise the right to self-government.

In addition, the selection of a working language is the major problem in multi-ethnic regions particularly in SNNP. In this regional state it is difficult to select working language in the existence of a dozen of languages spoken in the region. Berhanu Gutema stated that;

Although the constitution of the SNNP regional state proclaims that zonal and special wered councils have the right and duty in determining the working language of their respective administrative unit and protecting the rights of nationalities in their respective territory to speak, write and develop their languages, in the majority of cases the constitutional intention has remained theoretical. Only few zonal administration like Gedeo, Hadiya, Kembata, Sidama and Wolaita zonal administrations have introduced their languages in their respective zones. But in multiethnic zonal administrations such as Guraghe, Gamogofa, Benchi Majji, Debube Omo, and Sheka zones it has become difficult to select any of the indigenous languages for administrative purpose or in elementary education programmes. ${ }^{29}$

\section{Future Trends to Preserve Separate Identity}

It is difficult to talk about future trends to exercise the rights to preserve separate identity under the constitution. In our view the structure of the ethnic federalism in Ethiopia will be a source of human rights abuse particularly the right to preserve separate identity unless more flexible and workable formula is devised. In addition, feelings of separate identity lead to ethnic tensions and conflicts that finally endanger our national identity. Brhanu also, argued that Constructing and erecting ethnic pillars are very destructive in the long run due to the narrow and ego centric nature of ethnic demands. He also stated that ethnic federal political system and Ethnic demands are very difficult to satisfy the right to preserve separate identity in the short run particularly in poor societies like Ethiopia where resources are severely scarce, but ethnic demands need ample economic resource. For this reason, it is advisable to emphasize incentives for socio-political integration rather than focusing on differences. Based on this, We conclude that socio-economic and political integration among ethnic groups will be better to solve those tensions between ethnic groups. But the unity and integration will be conducted with the recognition and respect of ethnic groups and their legitimate claims.

\section{Conclusion}

In conclusion, the Ethiopian Constitution embodies a progressive

${ }^{28}$ Getachew, Assefa. (2011). Federalism and legal pluralism in Ethiopia: preliminary observations on their impacts on the protection of human rights, East African journal of peace and human rights, p: 180.

${ }^{29}$ Supra note. 2 p: 210. 
list of rights compared to its predecessors. The special features of the Constitution include the recognition given to the ethnic diversity and the willingness to accommodate it through the right to selfdetermination. The right of NNP to self-determination, up to secession includes the right to speak, write, develop their language; to express, promote and develop their culture; preserve their history; and to selfgovernment and equitable representation in the regional state and federal governments. The realization of these rights should result in unity in diversity, in the creation of an Ethiopian national identity through the respect for ethnic diversity. ${ }^{30}$

However, there is challenging task to protect the rights of one' identity of ethnic groups under the constitution due to the complex arrangement of the federal system. It is evident that with more than 80 ethno linguistic groups, it is a gigantic task in Ethiopia to satisfy the rights of all these groups to exercise their rights to separate identity except few rights. Although many of the ethnic groups find satisfaction

${ }^{30}$ Supra note. 1 p: 56 . in the ideological commitment behind the promise to recognize their identity, language and political rights, in most cases, however, they are disappointed with the actual implementation, which is devoid of genuine self-administration. Thus, the Ethiopian ethnic federal model is not successful in promoting the right to ethnic identity and autonomy except in few regions. ${ }^{31}$

In the future, ethnic federalism in Ethiopia will further exacerbated the growth of ethnic consciousness and ethnic classification which endanger our nation identity unless an appropriate measure should be taken. ${ }^{32}$ Thus, it is advisable to discourage ethnic criterion for political organization as much as possible in order to avoid ethnic tensions and conflicts that is a source of most human rights abuses in Ethiopia. So, it is better to facilitate socio-political integration all together with the recognition and respect of ethnic groups to exercise their legitimate claim.

${ }^{31}$ Supra note. 2 p: 124

${ }^{32}$ lbid pp: $271-272$ 